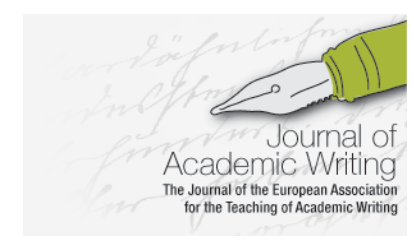

Journal of Academic Writing Vol. 8 No 2 Winter 2018, pages 89-113 http://dx.doi.org/10.18552/joaw.v8i2.447

\title{
Using Peer Review with Greek EFL College Students
}

\author{
Melpomeni llkos \\ Deree - The American College of Greece, Greece
}

\begin{abstract}
Peer review fosters student critical thinking and self-evaluation (Wood and Kurzel 2008). Numerous studies show that peer review is effective in improving student writing (Althauser and Darnall 2001, Bean 2011), and that it benefits the students receiving as well as those giving the feedback (van den Berg, Admiraal and Pilot 2006). However, these issues have not been greatly researched in Greece. Greek culture bestows great authority to the teacher and students are not accustomed to peer feedback.

I have embarked on a small-scale, exploratory, classroom-based study conducted at Deree The American College of Greece where English is the medium of instruction. Data include first and revised drafts of three academic writing assignments, written peer comments, and learner reflections on the peer reviewing experience. To further explore student attitudes toward peer review, I also administered an online questionnaire. Initial quantitative and qualitative analyses reveal (a) in general student reviewers and reviewees alike accept peer review as an appropriate pedagogical activity; (b) students revise their writing taking into account peer feedback and (c) as reviewers, students were not more critical in giving feedback when doing peer review anonymously. Preliminary results are interpreted with an understanding of the limitations of the ongoing study.
\end{abstract}

\section{Introduction}

Both the Greek Pedagogical Institute and the Ministry of Education (2003), in a report outlining the framework of study programs for foreign languages, have recommended student-centred approaches to teaching and learning. Yet, English as a Foreign Language (EFL) teaching has remained unchanged in Greece over the years since most of it is certificate oriented (Gabrielatos 2003). This emphasis on certified language proficiency leads to rigorous teachercentred approaches to language teaching and learning (Mattheoudakis 2007). It would therefore be interesting to explore Greek learners' perceptions on student-centred practices and, in particular, on peer review.

Peer review, also referred to as 'peer feedback', 'peer revision', or 'peer critique' (Hu 2005), which involves reading, critiquing and giving feedback on a classmate's writing (Tsui and $\mathrm{Ng}$ 2000), is a significant component of process writing (Paulus 1999, Wood and Kurzel 2008). As van den Berg, Admiraal and Pilot (2006) note, peer review equally benefits students giving and receiving feedback. Peer review is 'non-threatening' and beneficial to learning as students receive suggestions from their peers about how to improve their work (Wood and Kurzel 2008). Thus, there are benefits from encouraging students to review each other's work (Wessa and De Rycker 2010): the reviewee gets another viewpoint on how to enhance his/her work (Sims 1989), and the reviewer benefits from having to analyse the work of a peer (Wessa and De Rycker 2010). 
Findings on peer review in English as a Second Language (ESL) and/or EFL writing indicate that students prefer teacher feedback over peer feedback. However, much of the research made on peer review is carried out in the United States (USA) or Asia. One study by Paulus (1999) researched the influence of peer and teacher feedback on 11 international students enrolled in a pre-freshman writing class at a university in the USA whose mother tongues included Japanese, Taiwanese, Malay, Arabic and Portuguese. Results from the study indicated that learners used $87 \%$ teacher versus $51 \%$ of peer feedback when revising. Another study by Mangelsdorf (1992), which was carried out at a university in the USA, researched the attitudes of 40 advanced international ESL learners toward peer review, and determined that $69 \%$ of participants in the study had a positive opinion regarding the practice. In addition to researching student attitudes toward peer review, Connor and Asenavage (1994) also studied the influence of peer and teacher feedback on eight ESL students from different countries who were studying at a university in the USA. They reported that only $5 \%$ of revisions were correlated to peer feedback and 35\% to teacher feedback. A further study by Yang, Badger and $\mathrm{Yu}(2006)$ revealed that Chinese EFL college learners also employed more teacher (90\%) than peer feedback $(76 \%)$ in their revisions. The study concluded that although the participants found peer feedback useful, they strongly favored the value of teacher feedback (Yang, Badger and Yu 2006). All of these studies showed that participants seem to prefer teacher feedback because they trusted the teacher's knowledge of the language more than the knowledge of their peers.

The aim of this study is to investigate Greek EFL tertiary-level student attitudes toward peer review. The results of the study may lead to the reevaluation of EFL pedagogical practices in Greece.

\section{Literature Review}

The role of feedback on writing is multifaceted and needs to be considered in the context in which the feedback is given. In traditional student/teacher relationships, students tend to accept the authority of the teacher. To explore student attitudes toward peer review, literature was obtained from three areas:

- Benefits of peer review

- Student viewpoint of peer and teacher feedback

- Quality of peer feedback

\section{Benefits of peer review}

Peer review promotes learning as it allows students to reflect on their roles as writers and readers (Hu 2005). According to Vygotsky (1978), learning is a cognitive activity that is facilitated by social communication. Thus Vygotsky's view supports peer review as it is built around collaboration, with students working in groups or pairs seeking answers.

\section{Student viewpoint of peer and teacher feedback}

Generally students perceive peer review positively (Li and Steckelberg 2004) even though culture may determine actual use of peer feedback (Allaei and Connor 1990). Students accustomed to a teacher-centred classroom may not feel comfortable working with peers in a more student-centred environment and may resist group-centred peer review activities (Braine 2003). Students will not be able to generate very productive work (Carson and Nelson 1996, Nelson and Murphy 1993) if they are mistrustful of each other. Nelson and Murphy (1993), for example, reported that Chinese students rarely accepted other second language (L2) speakers of English to review their writing. In fact, students from countries that uphold power distance ${ }^{1}$ appear to have less regard for peer feedback than those from countries that exhibit lower power distance (Hu 2005, Jacobs et al. 1998, Nelson and Carson 1998). In environments where the

\footnotetext{
${ }^{1}$ Power distance refers to the degree to which the less powerful in a society accept the inequity in power and regard it as typical. Inequity exists within every culture, but the degree to which it is tolerated varies from one culture to another (Hofstede 1986).
} 
teacher is seen as the expert, the teacher remains at a psychological distance from the students.

According to Hofstede's (1986) theory of five dimensions to understanding cultural differences, the Greek culture tolerates power distance between those who are in authority (the teacher) and those who are not (the students). Greece belongs to high power distance cultures along with Italy, Spain, Taiwan, South Korea, Hong Kong, China and Japan (Hofstede 1986). Teachers in Greece typically take on the role of the expert who has the answers and are seldom challenged or questioned. Thus Greek students are comfortable with and accustomed to a teacher-centred, controlled environment with specific objectives and assignments.

In the European context, Coté (2013) studied 25 participants aged 18-25 from various linguistic and cultural backgrounds. 17 of the participants were Spaniards, three Arab students, two Chinese, one Central American, one South American and one student of mixed race (European and sub-Saharan African) who were taking an EFL writing class in Madrid, Spain. Results indicated that participants overwhelmingly accepted and included $70 \%$ of peer feedback in their revised drafts. A further study by Littlewood (2001) surveyed student attitudes toward classroom English learning in eight East Asian countries (Brunei, Mainland China, Hong Kong, Japan, South Korea, Malaysia, Thailand, Vietnam) and three European countries (Finland, Spain and Germany). Most of the participants were female tertiary level students. The focus of the study was on power and authority, and different types of achievement motivation. It was found that most participants in all the countries surveyed question the traditional authoritybased method of learning and had positive attitudes toward working in groups to achieve a common objective.

Regarding research focused on peer feedback in Greece, Anastasiadou and Aristotelous (2015) investigated attitudes toward peer feedback in two public primary schools in Northern Greece. Their results indicated that even though the Greek learning framework is not supportive of student collaboration, nevertheless 'notions of collaborative production of writing are proven to be viable options in the Greek classroom reality' (Anastasiadou and Aristotelous 2015: 394), as the young participants in the study appeared to recognize the importance of peer feedback. This is a significant finding and one which aligns with the study discussed here which investigated Greek EFL tertiary-level student perceptions and experiences toward peer review and also found that participants developed positive attitudes toward peer feedback. The literature reviewed here validates that exposure to process-writing and peer feedback techniques offer students insight into their own writing and allow them to benefit from their participation in the correction of their peers' writing.

\section{Quality of peer feedback}

Regardless of the benefits of peer review activities, there is apprehension among students on the quality of peer feedback. Literature suggests that peer reviewers may be biased and/or untruthful in giving feedback because of personal relationships or preferences (Carson and Nelson 1996, Nilson 2003, Zhao 1998). To increase and ensure quality of peer feedback, researchers support use of electronic communication (Eisenberg and Ely 1993, Mabrito 1991), and the use of numerous reviewers (Kerr, Park and Domazlicky 1995, Nilson 2003). To reduce dishonest feedback, anonymous peer review is recommended (Kerr, Park and Domazlicky 1995, Vinson 1996, Zhao 1998).

A further concern of $L 2$ students, with regards to peer review, is that the linguistic ability of their peers, who are still learning the target language, is not at a level proficient enough to provide valid feedback (Nelson and Murphy 1993, Rollinson 2005, Tsui and Ng 2000). Peer reviewers, as well as L2 novice writers, do not yet fully possess the target language or its rhetorical conventions; they, therefore, find it difficult to review peer texts and look skeptically at peer feedback.

Carson and Nelson (1996, see also Nelson and Carson 1998) carried out research on Chinese EFL college students and found that participants favored teacher feedback believing that since teachers know the English language better, they are able to provide more valuable feedback than peers. Yang, Badger and Yu (2006) also made a similar claim. Their study, which involved 
twelve Chinese EFL participants, found that students strongly favored teacher feedback and had doubts both about the accuracy and the value of peer feedback. In spite of these findings however, this does not imply that L2 learners find peer review to be a waste of time (Paulus 1999), rather students simply prefer receiving feedback from their teacher to that from their peers (Hu and Lam 2010).

While most of the literature reviewed here shows that students largely favored teacher feedback over peer feedback, there is at least one study in the literature that found favorable student opinions on peer review. Liu and Chai (2009) studied 84 advanced-level undergraduate Chinese EFL learners enrolled in a writing course. Of the 84 studied, 58 had never engaged in peer review before. Despite the fact that China is a country with high power distance: $77.4 \%$ of the participants believed that peer review was as valuable as teacher review, and $89.3 \%$ did not consider peer review to be a waste of time.

Despite the benefits of student participation in peer review, there is some concern about the quality of peer feedback. Lu and Bol (2007) compared the effects of anonymous and identifiable electronic peer review on college student writing performance and the degree of critical peer feedback. Members of the anonymous group believed 'it was easier for them to give and get honest and critical feedback under anonymous condition[s]' (Lu and Bol 2007: 110).

In studies by Zhao (1998) and Lu and Bol (2007), one of the measured indicators was also perception. Participants were asked to rate how they felt about the peer review process, the outcome and overall the activity. According to the Zhao (1998) study, at the tertiary-level student writers felt the reviewers were more critical when they were anonymous. 'The t-test indicated the difference was not statistically significant' (Zhao 1998: 330). However, at the same time the anonymous reviewers worked less. It seems anonymity has 'an effect on loafing' (Zhao 1998: 333). In other words, participants make less cognitive effort for a task when working anonymously.

Valacich, Dennis and Nunamaker (1992: 61) conducted a laboratory experiment to examine the effects of group size and anonymity and reported that 'anonymous group members were more critical than identified group members; members of large groups were more critical than members of small groups; and small-identified groups were the least critical'.

\section{Current Study}

This paper reports on a classroom-based study that investigated the attitudes of Greek tertiarylevel EFL students' toward peer review. Specifically, the aim of the study was to explore Greek learner perceptions and experiences about: peer review in academic writing classes; the benefits of using peer review activities in class; and possible concerns regarding the use of peer review activities.

\section{Methodology}

\section{Setting and participants}

Deree - The American College of Greece (ACG) is a private, 145 year old institution, the largest and oldest US accredited college in Europe, located in Athens. The students are mainly Greek however the student body, in total, consists of students from over 50 countries, a large proportion of these being from the Middle East. Thus, Deree has an international student body who do not share a common first language; however, English is used as the medium of instruction and in all formal and informal teacher-student interactions.

Participants in this study were all Greek tertiary-level EFL learners enrolled in WP1010 Introduction to Academic Writing, a class designed for undergraduate freshmen at ACG. The Greek pedagogy is very much teacher-centred with the teacher having primarily the role of the reviewer and evaluator. Hence in the Greek educational culture, the teacher is given great authority. 
Table 1, below, gives a detailed breakdown of the participants' age, gender, experience with peer review, and perceived English ability:

Table 1. Participants in the study

\begin{tabular}{|l|l|l|l|}
\hline Gender & Age & $\begin{array}{l}\text { Previous experience with peer } \\
\text { review }\end{array}$ & Self-perception of level \\
\hline 16 male & $\begin{array}{l}18-20(15 / 16) \\
21-25(1 / 16)\end{array}$ & $\begin{array}{l}\text { Never: }(6 / 16)=37 \% \\
\text { Once or twice: }(8 / 16)=50 \% \\
\text { More than twice: }(2 / 16)=13 \%\end{array}$ & $\begin{array}{l}\text { Nativelike: }(4 / 16)=25 \% \\
\text { Advanced: }(10 / 16)=62 \% \\
\text { Intermediate: }(2 / 16) 13 \%\end{array}$ \\
\hline 19 female & $\begin{array}{l}18-20(17 / 19) \\
21-25(2 / 19)\end{array}$ & $\begin{array}{l}\text { Never: }(7 / 19)=37 \% \\
\text { Once or twice: }(4 / 19)=21 \% \\
\text { More than twice: }(8 / 19)=42 \%\end{array}$ & $\begin{array}{l}\text { Nativelike: }(4 / 19)=21 \% \\
\text { Advanced: }(9 / 19)=47 \% \\
\text { Intermediate: }(6 / 19)=32 \%\end{array}$ \\
\hline $\begin{array}{l}\text { Total: } \\
35\end{array}$ & $\begin{array}{l}\text { 18-20 =32/35 } \\
21-25=3 / 35\end{array}$ & $\begin{array}{l}\text { Total: } \\
\text { Never: }(13 / 35)=37 \% \\
\text { Once or twice: }(12 / 35)=34 \% \\
\text { More than twice: }(10 / 35)=29 \%\end{array}$ & $\begin{array}{l}\text { Total: } \\
\text { Nativelike: }(8 / 35)=23 \% \\
\text { Advanced: }(19 / 35)=54 \% \\
\text { Intermediate: }(8 / 35)=23 \%\end{array}$ \\
\hline
\end{tabular}

\section{Data collection and procedure}

Data were collected from three sections of WP1010 offered by the same instructor (namely the researcher) over a period of two semesters (September 2016-December 2016 and January 2017-April 2017). ${ }^{2}$ Students had three 50-minute classes per week for 14 weeks (a total of 42 sessions). Through process-oriented writing (brainstorming, outlining, drafting and revising), they were introduced to academic discourse, practiced analytical reading skills, objectively presented the arguments of others, and critically responded to texts with their own arguments.

The course was thematically structured. Two sections (which took place in the first semester: September-December 2016) focused on gender differences in communication, and one section (which took place in the second semester: January-April 2017) focused on English as a lingua franca. Each of the three sections required three summative assessments: a 500-600 word thematic summary essay, a 750-850 word critical response essay, and a 1000-1100 extended critical response essay. Students received a prompt that included writing guidelines for each assignment.

Data included first drafts of three academic writing assignments from 35 students (outlined in Table 1), 35 written peer comments on each of the three assignments, and 35 responses to an online questionnaire, created by the researcher through Google Forms (Appendix I), which was specifically designed to investigate student perceptions of the value of peer feedback. The questionnaire took into consideration a methodologically similar study that examined Chinese EFL university student attitudes toward, and reaction to, peer review (see Liu and Chai 2009). It included both multiple-choice and open-ended questions and was administered at the end of both semesters to 35 students and gathered 35 responses. Students were asked about their previous experiences of peer feedback, their peer feedback preferences and their beliefs about the helpfulness of various forms of feedback. They were also asked to identify the actions they took as a result of the peer feedback. To allow students to express themselves freely, the questionnaire was submitted anonymously. The data collected from the online questionnaire indicated that more than half of the participants had some experience with peer review at ACG.

At the beginning of this study, the teacher/researcher briefly explained to the students the importance of analysing each other's work, and explained the benefits and potential pitfalls of

2 The institution granted the author permission to conduct this project involving the author's students. The students signed a consent form in which they granted the author permission to use their comments anonymously. 
peer review. The students were also given the readings at the start of the semester which were extensively discussed in class, the prompt and the analytical rubric for each assignment.

Each time peer review sessions were held, students reviewed the work of a different student. For the first two assignments, students were engaged in guided peer review sessions individually offering written feedback responding to questions using a relevant feedback worksheet (see Appendix II). In the third assignment, students performed peer review working in pairs to exchange written and oral feedback. In order to relate peer review with the learning outcomes of the course, the worksheets included global questions on content only: unity and coherence, use of sources, use of own voice and ideas for improvement. The last question asked the reviewer to reflect on the process and to state one thing he/she had learned from the peer review exercise. Table 2 presents a sample of observations made from student responses to the final question on these feedback worksheets.

Table 2. 'State one thing you learned from this peer review exercise'

\begin{tabular}{|l|}
\hline I like the way the writer used Quindlen's opinion about "fundamentally alike." \\
\hline$[\ldots]$ data for the refutation and a new method for starting an essay. Thanks. \\
\hline Bringing in personal experience into the essay makes it more vivid. \\
\hline My peer uses great transitions which is something I have found myself to be weak in. \\
\hline
\end{tabular}

Peer review occurred in class, when students submitted the first draft of each summative assignment, and lasted for one class session (50 minutes). Since anonymity was not the main focus of this study, students agreed that they would submit named drafts while the peer reviewers could identify themselves at will. So, the reviewer knew the name of the writer, but the peer reviewers were free to decide if they wished to sign the report or perform their review anonymously. All students had the same risk since all of them were reviewers and reviewees and thus the mitigating risk was balanced.

Subsequent to the peer review process, the teacher/researcher gave written feedback on the drafts (distributed outside the class) and linked summary comments to peer feedback (Table 3). Students had at least one week to revise the draft, taking into consideration teacher and peer feedback. They were also encouraged to meet with the teacher during office hours for further assistance.

Table 3. Sample teacher summary comments: essay's strengths and guidance for improvement

You refer to Wallraff's article only once and zero to McWhorter's [...] Maria ${ }^{3}$ also tells you in the worksheet feedback.

The draft is full of repetitive, wordy phrases and citation problems [...] John also tells you this in the peer review worksheet.

Also see the comments made by the peer reviewer in the worksheet.

Alexandra also tells you in the peer review worksheet that you need more powerful arguments.

Margarita addresses these issues in her marginal comments. So read her comments.

${ }^{3}$ Student names are pseudonyms 


\section{Findings}

Overall, the findings of this small-scale study indicate that the research participants: (a) accept and value peer review as an appropriate pedagogical activity; (b) as reviewers, they believe that they have benefitted from evaluating the work of their peers; (c) as reviewees, take into account peer feedback in their revisions (a higher percentage of female over male students); and (d) do not appear to be more critical in giving feedback anonymously.

\section{Questionnaire results}

The results of the questionnaire were tabulated separately for female and male students in the role of the reviewer (Table 4) and of the reviewee (Table 5). This division had not been originally planned (i.e. gender was not one of the criteria for this study), but came about from observing the commitment of female students during the in-class peer review activities.

Table 4. Student perceptions of peer review in the role of a reviewer

\begin{tabular}{|c|c|c|}
\hline Questions & Female responses & Male responses \\
\hline $\begin{array}{l}\text { I found peer review helped me improve } \\
\text { the overall organization in my writing. }\end{array}$ & $\begin{array}{l}\text { No }=16 \% \\
\text { Yes }=84 \%\end{array}$ & Yes $=100 \%$ \\
\hline I performed peer review carefully. & $\begin{array}{l}\text { Always }=63 \% \\
\text { Most of the time }=37 \%\end{array}$ & $\begin{array}{l}\text { Always }=37 \% \\
\text { Most of the time }=44 \% \\
\text { Sometimes }=19 \%\end{array}$ \\
\hline $\begin{array}{l}\text { I was more critical in giving feedback } \\
\text { when I was doing peer review } \\
\text { anonymously. }\end{array}$ & $\begin{array}{l}\text { No }=68 \% \\
\text { Yes }=32 \%\end{array}$ & $\begin{array}{l}\text { No }=69 \% \\
\text { Yes }=31 \%\end{array}$ \\
\hline $\begin{array}{l}\text { I prefer to know the name of my peer } \\
\text { reviewee. }\end{array}$ & $\begin{array}{l}\text { No }=58 \% \\
\text { Yes }=42 \%\end{array}$ & $\begin{array}{l}\text { No }=50 \% \\
\text { Yes }=50 \%\end{array}$ \\
\hline $\begin{array}{l}\text { I was able to identify most of the } \\
\text { problems in the writing. }\end{array}$ & $\begin{array}{l}\text { Sometimes }=53 \% \\
\text { Most of the time }=42 \% \\
\text { Always }=5 \%\end{array}$ & $\begin{array}{l}\text { Sometimes }=56 \% \\
\text { Most of the time }=31 \% \\
\text { Always }=7 \% \\
\text { Rarely }=6 \%\end{array}$ \\
\hline $\begin{array}{l}\text { I found the combination of peer oral } \\
\text { conferencing and written comments } \\
\text { more helpful than just written comments. }\end{array}$ & $\begin{array}{l}\text { No }=10 \% \\
\text { Yes }=53 \% \\
\text { The same }=37 \%\end{array}$ & $\begin{array}{l}\text { No }=19 \% \\
\text { Yes }=31 \% \\
\text { The same }=50 \%\end{array}$ \\
\hline $\begin{array}{l}\text { I found peer review to be a waste of } \\
\text { time. }\end{array}$ & $\begin{array}{l}\text { No }=95 \% \\
\text { Yes }=5 \%\end{array}$ & $\begin{array}{l}\text { No }=81 \% \\
\text { Yes }=19 \%\end{array}$ \\
\hline
\end{tabular}


Table 5. Student perceptions of peer review in the role of a reviewee

\begin{tabular}{|l|l|l|}
\hline Questions & Female responses & Male responses \\
\hline I read peer feedback carefully. & $\begin{array}{l}\text { Always }=69 \% \\
\text { Most of the time }=26 \% \\
\text { Sometimes }=5 \%\end{array}$ & $\begin{array}{l}\text { Always }=19 \% \\
\text { Most of the time }=62 \% \\
\text { Sometimes }=19 \%\end{array}$ \\
\hline $\begin{array}{l}\text { I found peer feedback to be as } \\
\text { valuable as teacher review. }\end{array}$ & $\begin{array}{l}\text { Most of the time }=10 \% \\
\text { Sometimes }=58 \% \\
\text { Rarely }=32 \%\end{array}$ & $\begin{array}{l}\text { Most of the time }=13 \% \\
\text { Sometimes }=37 \% \\
\text { Rarely }=31 \% \\
\text { Never }=19 \%\end{array}$ \\
\hline $\begin{array}{l}\text { I revise my writing taking into account } \\
\text { peer feedback. }\end{array}$ & $\begin{array}{l}\text { Always }=32 \% \\
\text { Most of the time }=37 \%\end{array}$ & $\begin{array}{l}\text { Most of the time }=50 \% \\
\text { Sometimes }=38 \% \\
\text { Rarely }=12 \%\end{array}$ \\
\hline $\begin{array}{l}\text { I prefer to know the name of my peer } \\
\text { reviewer. }\end{array}$ & $\begin{array}{l}\text { No }=37 \% \\
\text { Yes }=63 \%\end{array}$ & $\begin{array}{l}\text { No }=56 \% \\
\text { Yes }=44 \%\end{array}$ \\
\hline $\begin{array}{l}\text { I found the combination of peer oral } \\
\text { conferencing and written comments } \\
\text { more helpful than just written } \\
\text { comments. }\end{array}$ & $\begin{array}{l}\text { No }=21 \% \\
\text { Yes }=42 \% \\
\text { The same }=37 \%\end{array}$ & $\begin{array}{l}\text { No }=12 \% \\
\text { Yes }=44 \% \\
\text { The same }=44 \%\end{array}$ \\
\hline $\begin{array}{l}\text { I found peer review to be a waste of } \\
\text { time. }\end{array}$ & $\begin{array}{l}\text { No }=95 \% \\
\text { Yes }=5 \%\end{array}$ & $\begin{array}{l}\text { No }=81 \% \\
\text { Yes }=19 \%\end{array}$ \\
\hline
\end{tabular}

\section{Discussion}

\section{Value of peer review}

By providing students with a friendly, supportive learning environment, student learning anxiety was reduced and students were, therefore, open to receive and offer peer feedback. The Greek tertiary-level EFL students involved in this study hold exceptionally favorable views about peer review as revealed by their comments in Tables 6 to 9 , below.

\section{Table 6. Sample comments made by female students in the role of a reviewer}

As a reviewer I have the chance to see different writing styles, more ideas and learn new words to improve my vocabulary.

$[\ldots]$ because I can help my peer.

[...] because I think I helped the other person become a better writer than before.

It helped me in communicating with my classmates and respecting opposite ideas.

I found very interesting this idea [peer review] because I see many mistakes in many areas.

I tried to make comments, so my classmates could have a second opinion and I think that was helpful because I personally was benefited from their peer reviews!

[...] because I could later reduce my mistakes. 


\section{Table 7. Sample comments made by female students in the role of a reviewee}

[...] getting to know what other readers-students (who also try to do the same assignment) (except for my professor) think of my assignments; [peer review] is helpful because they provide suggestions from another perspective and thus helping me improve.

I can see my peer's opinion about my work.

Because it is the reviewer that helps the reviewee improve his/her essay and vice versa. Also while the reviewer comments on the essay, at the same time he/she learns about him/herself and how to improve their own essay. So it is a bonus for both.

A lot of times I'm able to distinguish mistakes I have also made but wasn't able to locate in my own work.

It showed me that I could easily find errors in other papers and I found some in my papers by pretending it wasn't mine.

It helps me correct my mistakes and understand them so that I don't make them again.

[...] because it improves my draft also, I found mistakes that I may have done them at my draft and I see also different ideas.

Someone else's comments help me see out of the box and understand my mistakes; also the fact that we are "judged" by my classmates make it more fun and help us come closer in a way!

Table 8. Sample comments made by male students in the role of a reviewer

It [peer review] helped me understand my mistakes.

This way you come into the teacher's position and you learn how to evaluate yourself as well as other papers!

I got some ideas that I implemented in my own text.

The reviewer can see mistakes in your easy that you don't see. Also this is helpful because in your next essay you will be able to correct your mistakes.

Personally, I believe it [peer review] makes you better.

[...] because it [peer review] is a process that can help students improve their writing.

Table 9. Sample comments made by male students in the role of a reviewee

It helps me as a reviewer seeing other people's ideas and mistakes.

Got ideas about organization.

Because, it [peer review] helps students improve their writing.

I found some mistakes in my paper.

Help me to develop my writing in all fields. 
Additional statistical data show that 95\% female and $81 \%$ male students believed peer review to not be a waste of time. Moreover, female and male students alike believed they have benefitted from doing peer review - in accordance with findings that L2 writing students can improve their own writing by transferring abilities they learn when reviewing peer texts (Lundstrom and Baker 2009). Finally, 84\% female and 100\% male students stated that peer review helped them improve their overall organization. Coté (2014) also indicated that student writers overwhelmingly accepted and included peer feedback in their revised drafts.

However, there are some students who expressed doubts concerning the usefulness of peer review. Their comments, appearing in Table 10, below, reveal their wariness which perhaps stems from their peers' level of proficiency in English. As Diab (2010) has noted, EFL learners are unable to identify all the mistakes and problems in their classmates' texts.

Table 10. Comments made by male students in the role of a reviewee/reviewer

Mostly because there are more specialized reviewers that can do this job of peer review.

It could become misleading and not help at all but it's not that it's a completely waste of time.

\section{Attention given to peer feedback}

Female students, as reviewers or reviewees, were more immersed in the peer review process than male students. Duckworth and Seligman (2006) conducted a longitudinal study of 198 eighth-grade students (13-14 years old) to investigate the difference in gender around selfdiscipline, grades, and achievement test scores. Their results indicated that girls were 'more self-disciplined than boys' (Duckworth and Seligman 2006: 206), but it is not certain if gender differences in self-discipline continue into adulthood (18 - 24 years old). Steinmayr and Spinath (2008) sampled 204 female and 138 male 11th and 12th graders attending a high school in Germany preparing for university. The focus of the study was to research sex differences in school achievement and the roles of personality and achievement motivation. Their data complemented the findings of Duckworth and Seligman (2006) in that the girls do better than boys in overall grade average. Steinmayr and Spinath (2008: 202) 'partly attributed [this] to girls' higher agreeableness and lesser tendency to avoid work'. The results of the female participants in the current study supported the Duckworth and Seligman (2006) and the Steinmayr and Spinath (2008) findings. The female participants in this study complied with the instructional recommendation to perform peer review and thus they were more engaged in the activities than the male participants (Table 4).

\section{Value of peer feedback compared to teacher feedback}

It is also worth observing that although participants in this study come from a culture that places great value on power distance, and overall they regard teacher feedback to be more valuable, female participants perceived peer feedback to be as valuable as teacher feedback. Results showed that $10 \%$ of female students found peer feedback useful most of the time, $58 \%$ found it useful sometimes, while only $32 \%$ found it rarely so. In contrast, while a slightly higher $13 \%$ of male students found peer feedback as valuable as teacher feedback most of the time, $37 \%$ found it useful sometimes, while $31 \%$ said they rarely found it useful, and $19 \%$ found it never to be so (Table 5).

Hu and Lam (2010) studied twenty L2 learners from China who were enrolled in a postgraduate academic writing class at a university in Singapore. They admit their participants' strong preference for teacher feedback and note that their L2 learners mistrust the accuracy and validity of peer comments (Hu and Lam 2010). One of the biggest concerns among L2 learners is that their peers are not proficient enough to provide feedback (Tsui and $\mathrm{Ng} \mathrm{2000,} \mathrm{Rollinson}$ 2005). However, participants in the current study were fairly positive about the overall value of peer review. This result aligns with conclusions found by Liu and Chai (2009) who reported that $13 \%$ of their participants, also coming from a country that values power distance, considered peer review more effective than teacher review and $77 \%$ of the participants viewed it as valuable as the teachers.' 


\section{Use of peer feedback}

A higher percentage of female students in this study stated that they incorporated peer feedback when they revised their work. Specifically, 32\% claimed they always revised their writing taking into account peer feedback, $37 \%$ said they did this most of the time and $31 \%$ sometimes. In contrast, half of the males admitted to considering peer remarks when revising most of the time, $38 \%$ sometimes, and $12 \%$ do so rarely.

The current study did not aim to examine the degree to which female and male students are committed to peer review, but these results provide preliminary evidence that female students engaged more in the peer review process.

\section{Anonymity and criticality}

As previously discussed, in this study the student writers were identifiable while the peer reviewers were free to decide if they wished to remain anonymous or reveal their identity. As reviewers, most students replied they were not more critical in giving feedback when doing peer review anonymously. Specifically, $68 \%$ female and $69 \%$ male students said they were not more critical in giving feedback when doing peer review anonymously. This finding is not aligned with the Zhao (1998) and Lu and Bol (2007) studies that supported anonymity elicits more critical feedback.

The data in this study also suggest that the participants as reviewers, members of a small group, perceived they were not more critical toward their peers when they were identifiable. This finding is not aligned with the Valacich, Dennis and Nunamaker (1992) study that supported anonymity, group size and criticality. This issue needs to be further explored (perhaps by examining the actual peer feedback given).

As reviewees, over half of the female students (63\%) and close to a half of the male students (44\%) who took part in my study stated that they would prefer to know the name of their peer reviewer. Literature, however, supports anonymity so peer reviewers can provide fair and unbiased feedback. Li and Steckelberg (2004: 582) explored the effect of anonymous peer feedback. One participant identified that 'it helped out not knowing who the person was critiquing my project' and another that 'it probably puts less pressure on the grader'.

Finally, participants overall agreed on the effectiveness of combined oral and written feedback in the improvement of their writing attitude and skills (Suh 2005). 53\% female and 31\% of male reviewers reacted positively to the idea of pairing up and receiving oral and written peer feedback, whereas $37 \%$ of female participants and $50 \%$ of male participants reported they found the experience to be the same. Finally, only $10 \%$ of female and $19 \%$ of male students responded negatively to the question: 'I found the combination of peer oral conferencing and written comments more helpful than just written comments'.

\section{Table 11. Comments made by reviewers}

Because when I know the name, then I can go up to them and explain if there's any misunderstanding in my comments and I can have a discussion with them.

[...] because I want to know the person I am going to evaluate.

Because after the review, they can come and ask me questions even though that rarely happens.

As reviewees, $42 \%$ of the female students found the combination of oral and written peer feedback more helpful than just written feedback, $37 \%$ found both oral and written feedback as helpful, and only $21 \%$ did not find it more helpful. On the other hand, $44 \%$ of the male students found the combination of oral and written peer feedback more helpful than just written feedback, $44 \%$ found both oral and written as helpful, and only $12 \%$ did not find it more helpful. Students showed a general agreement about the facilitative role of both written and oral feedback in the improvement of writing. According to Chamot and O'Malley (1994), when learners have a 
chance to orally express their ideas to others in conferences, their writing ability is improved. During a conference, a writer negotiates the meaning of the ideas and receives feedback on the spot which can be included in the revision. Student writers have the opportunity to discuss their ideas with peers and offer clarifications. This collaboration assists students both as reviewees and reviewers to support their views and reflect on their writing. Also in small group settings (as in this study) when students communicate with one another in order to give and receive feedback, they become even more familiar with each other and they might be more open to the feedback received.

\section{Limitations and Suggestions for Future Research}

The results of this small classroom-based study are interpreted with an understanding of the limitations. It may be important to train Greek tertiary level students in how to conduct peer review. This may help students improve the quality of the feedback and more importantly, comprehend the importance of peer feedback in the revision process.

Anonymity is another factor that could be considered. If both the reviewee and the reviewer are anonymous, the feedback offered might be even more critical and meaningful. Student writers would submit unnamed drafts using their student identification number. It would be noteworthy to compare anonymous versus named reviews.

This is an on-going study and the follow-up is to examine whether actual changes in the revisions resulted from peer or teacher feedback and if, indeed, the use of anonymity did not result in more critical feedback. Also of interest might be whether gender of reviewer contributes to reviewee's reaction to comments as the data analysis seemed to suggest that there were differences.

\section{Conclusions}

This study is best seen as investigative in nature and as a catalyst for further research. However, from the results reported, some preliminary conclusions may be drawn.

First, one can cautiously claim that the results of this study are reasonably positively aligning with Hu (2005), Jacobs et al. (1998), Paulus (1999), and Yang, Badger and Yu (2006). Greek tertiary-level EFL students do consider peer feedback to be useful even though they are accustomed to a teacher-centred classroom and we might have expected them to not feel comfortable working with peers in a more student-centred environment (Braine 2003). However, the majority of the participants (95\% female and 81\% male reviewers and reviewees) expressed a strong positive value for peer review. This result aligns with Liu and Chai (2009) finding that $89.3 \%$ of their Chinese EFL participants in writing classrooms believed in the usefulness of peer review.

Second, although the Greek EFL students in this study regarded teacher feedback to be more valuable, $20 \%$ of both female and male students regarded peer feedback as valuable as teacher feedback, and $40 \%$ sometimes peer feedback to be as valuable as teacher feedback. This finding to a certain extent parallels that of Liu and Chai (2009) who reported that $77 \%$ of their participants considered peer review to be as valuable as teacher review.

Generally speaking, Greek EFL students, coming from a teacher-centred culture, appeared initially skeptical about the significance of peer review. Perhaps they believed that only teachers have the knowledge and expertise to review their work and as a consequence they mistrusted peer feedback (Nelson and Murphy 1993, Paulus 1999). Thus, it is imperative for instructors to emphasize and explain repeatedly the advantages of peer review and carefully organize peer review sessions in order to lessen possible problems such as student anxiety in relation to language problems (Nelson and Carson 1998). 
A third noteworthy result is the higher percentage of female students who claimed to revise their writing taking into account peer feedback. This finding corresponds with Duckworth and Seligman (2006) and Steinmayr and Spinath (2008) findings in that female students are more self-disciplined and accommodating. It seems gender characteristics and qualities may not be culture specific.

Lastly as reviewers, most students believed they were not more critical in giving feedback when doing peer review anonymously. This is not consistent with Lu and Bol (2007) and Zhao (1998); their participants believed anonymity in peer review elicits more critical feedback. Of course, this finding is informative since it measures perceptions and not actual feedback given. To gain more in-depth understanding of the relation of anonymity and criticality for Greek EFL tertiarylevel students, the type and amount of actual peer feedback given should be examined further.

The affirmative results in this study suggest that Greek EFL tertiary-level students seem to have realized that by taking part in peer review activities they develop their linguistic and metacognitive abilities. Thus, these findings indicate that a more student-centred environment is a feasible alternative in the Greek classroom experience even though the Greek learning setting is not very supportive, despite the recommendations of the Greek Pedagogical Institute and the Ministry of Education (2003).

\section{Acknowledgements}

I would like to thank Dr. Evangelia Strantzali and Dr. Hariclea Zengos for their valuable comments on earlier drafts of the article. 


\section{References}

Allaei, S. K., and Connor, U.M. (1990) 'Exploring the Dynamics of Cross-Cultural Collaboration in Writing Classrooms'. The Writing Instructor 10, 19-28

Althauser, R., and Darnall, K. (2001) 'Enhancing Critical Reading and Writing through Peer Reviews: An Exploration of Assisted Performance'. Teaching Sociology 29 (1), 23-35

Anastasiadou, A., and Aristotelous, P. (2015). 'Feedback Revisited: The Impact of Peer Commentary on Students' Attitudes and Writing Performance in the EFL Classroom'. An-Najah University Journal for Research Humanities [Online] 29 (2), 369-402. available from <https://repository.najah.edu/bitstream/handle/20.500.11888/2329/6_OEYxRh0.pdf> [16 May 2018]

Bean, J. C. (2011) Engaging Ideas: The Professors' Guide to Integrating Writing, Critical Thinking and Active Learning in the Classroom. San Francisco, CA: Jossey-Bass

Braine, G. (2003) 'From a Teacher-Centred to a Student-Centred Approach: A Study of Peer Feedback in Hong Kong Writing Classes'. Journal of Asian Pacific Communication 13, 269-288

Carson, J. G., and Nelson, G. L. (1996) 'Chinese Students' Perceptions of ESL Peer Response Group Interaction'. Journal of Second Language Writing 5, 1-19

Chamot, A.U., and O'Malley, J.M. (1994) The CALLA Handbook: Implementing the Cognitive Academic Language Learning Approach. New York: Addison-Wesley

Connor, U., and Asenavage, K. (1994) 'Peer Response Groups in ESL Writing Classes: How Much Impact on Revision?' Journal of Second Language Writing 3 (3), 257-276

Coté R.A. (2014) 'Peer Feedback in Anonymous Peer Review in an EFL Writing Class in Spain'. Gist Education and Learning Research Journal 9, 67-87

Diab, N. M. (2010) 'Effects of Peer- Versus Self-Editing on Students' Revision of Language Errors in Revised Drafts'. System 38 (1), 85-95

Duckworth, A. L., and Seligman, M. E. P. (2006) 'Self-Discipline Gives Girls the Edge: Gender in Self-Discipline, Grades, and Achievement Test Scores'. Journal of Educational Psychology 98 (1), 198-208

Eisenberg, M. B., and Ely, D. P. (1993) 'Plugging into the Net'. ERIC Review [online] 2 (3), 210. available from <https://files.eric.ed.gov/fulltext/ED355940.pdf> [12 September 2016]

Gabrielatos, C. (2003) 'Greek Results in the Cambridge ESOL CPE Exams: Brief Analysis and Explanations'. ELT News [online] 167. available from

<https://www.academia.edu/3007250/Gabrielatos_C._2003_._Greek_results_in_Cam bridge_ESOL_CPE_exams_Brief_analysis_and_explanations._ELT_News_167_7?a uto $=$ download $>$ [27 May 2018]

Hofstede, G. (1986) 'Cultural Differences in Teaching and Learning'. International Journal of Intercultural Relations [online] 10, 301-320. available from

$<$ https://cdn.southampton.ac.uk/assets/imported/transforms/contentblock/UsefulDownloads_Download/556FF0E46EA742B2822ED2D32D89EA74/Hofst ede\%20(1986)\%20Cultural\%20differences\%20in\%20Teaching\%20and\%20Learning. pdf> [15 May 2018] 
Hu, G. (2005) 'Using Peer Review With Chinese ESL Student Writers'. Language Teaching Research 9 (3), 321-342

Hu, G., and Lam, S. T. E. (2010) 'Issues of Cultural Appropriateness and Pedagogical Efficacy: Exploring Peer Review in a Second Language Writing Class'. Instructional Science 38 (4), 371-394

Jacobs, G.M., Curtis, A., Braine, G., and Huang, S.Y. (1998) 'Feedback on Student Writing: Taking the Middle Path'. Journal of Second Language Writing 7, 307-317

Kerr, P. M., Park, K. H., and Domazlicky, B. R. (1995) 'Peer Grading of Essays in a Principles of Microeconomics Course'. Journal of Education for Business, 356-361

Li, L., and Steckelberg, A. (2004) 'Using Peer Feedback to Enhance Student Meaningful Learning'. Association for Educational Communications and Technology. held 19-23 October, Chicago IL. 576-587

Littlewood, W. (2001). 'Students' Attitudes to Classroom English Learning: A Cross-Cultural Study'. Language Teaching Research 5 (1), 3-28

Liu, M., and Chai, Y. (2009) 'Attitudes Towards Peer Review and Reaction to Peer Feedback in Chinese EFL Writing Classrooms'. TESL Reporter [online] 42 (1), 33-51. available from

<http://www.academia.edu/12369334/Attitudes_Towards_Peer_Review_and_Reactio n_to_Peer_Feedback_in_Chinese_EFL_Writing_Classrooms> [12 September 2016]

Lu, R., and Bol, L. (2007) 'A Comparison of Anonymous Versus Identifiable e-Peer Review on College Student Writing Performance and the Extent of Critical Feedback'. Journal of Interactive Online Learning [online] 6 (2), 100-114. available from <http://www.ncolr.org/jiol/> [27 October 2016]

Lundstrom, K., and Baker, W. (2009) 'To Give Is Better than to Receive: The Benefits of Peer Review to the Reviewer's Own Writing'. Journal of Second Language Writing 18 (1), 30-43

Mabrito, M. (1991) 'Electronic Mail as a Vehicle for Peer Response'. Written Communication 8 (4), 509-532

Mangelsdorf, K. (1992) 'Peer Reviews in the ESL Composition Classroom: What Do the Students Think?' ELT Journal 46, 274-284

Mattheoudakis, M. (2007) 'Tracking Changes in Pre-service EFL Teacher Beliefs in Greece: A Longitudinal Study'. Teaching and Teacher Education 23, 1272-1288

Nelson, G.L., and Carson, J.G. (1998) 'ESL Students' Perceptions of Effectiveness in Peer Response Groups'. Journal of Second Language Writing 7, 113-131

Nelson, G. L., and Murphy, J. M. (1993) 'Peer Response Groups: Do L2 Writers Use Peer Comments in Writing Their Drafts?' TESOL Quarterly 27, 135-142

Nilson, L. B. (2003) 'Improving Student Peer Feedback'. College Teaching 51 (1), 34-39

Paulus, T.M. (1999) 'The Effect of Peer and Teacher Feedback on Student Writing'. Journal of Second Language Writing 8, 265-289

Pedagogical Institute (2003) 'Cross Curricular/Thematic Framework'. [online] available from <http://www.pi-schools.gr/lessons/english/pdf/14depps_XenonGlosson-Agglika.pdf> [16 May 2018] 
Rollinson, P. (2005) 'Using Peer Feedback in the ESL Writing Class'. ELT Journal 59 (1), 2330

Sims, G. K. (1989) 'Student Peer Review in the Classroom: A Teaching and Grading Tool'. Journal of Agronomic Education [online] 18 (2), 105-108. available from <https://www.agronomy.org/files/publications/jnrlse/pdfs/jnr018/018-02-0105.pdf> [25 November 2016]

Steinmayr, R., and Spinath, B. (2008) 'Sex Differences in School Achievement: What Are the Roles of Personality and Achievement Motivation?' European Journal of Personality 22 (3), 185-209

Suh, J. (2005) 'Peer Feedback Interactions in EFL Compositions: Written Feedback versus Oral Feedback'. English Teaching 60 (4), 91-116

Tsui, A. B. M., and Ng, M. (2000) 'Do Secondary L2 Writers Benefit from Peer Comments?' Journal of Second Language Writing 9 (2), 147-170

Valacich, J., Dennis, A. R., and Nunamaker, J. F. (1992) 'Group Size and Anonymity Effects on Computer-mediated Idea Generation'. Small Group Research 23 (1), 49-73

van den Berg, I., Admiraal, W., and Pilot, A. (2006) 'Design Principles and Outcomes of Peer Assessment in Higher Education'. Studies in Higher Education [online] 31 (3), 341-356. available from <http://dx.doi.org/10.1080/03075070600680836> [25 November 2016]

Vinson, M. N. (1996) 'The Pros and Cons of 360-degree Feedback: Making It Work'. Training and Development 50 (4), 11-14

Vygotsky, L. S. (1978) Mind in Society: The Development of Higher Psychological Processes. Cambridge, MA: Harvard University Press

Wessa, P., and De Rycker, A. (2010) 'Reviewing Peer Reviews - A Rule-based Approach'. Proceedings of 5th International Conference on e-Learning. [online] 408-418. available from <http://www.wessa.net/download/icel10.pdf> [22 November 2016]

Wood, D., and Kurzel, F. (2008) 'Engaging Students in Reflective Practice through a Process of Formative Peer Review and Peer Assessment'. ATN Assessment Conference 2008: Engaging Students in Assessment [online]. available from <http://www.ojs.unisa.edu.au/index.php/atna/article/download/376/252> [22 November 2016]

Yang, M., Badger, R., and Yu, Z. (2006) 'A Comparative Study of Peer and Teacher Feedback in a Chinese EFL Writing Class'. Journal of Second Language Writing, 15 (3), 179-200

Zhao, Y. (1998) 'The Effects of Anonymity on Computer-mediated Peer Review'. International Journal of Educational Telecommunication 4 (4), 311-345 


\section{Appendix 1: Questionnaire - Powered by: Google Forms}

Peer Review - Learner Reflection

* Required

\section{Background}

1.

Gender *

Mark only one oval.

\section{Male}

Female

2.

Age *

Mark only

one oval.

$18-20$

21-25

26-30

3.

What is your major at ACG? *

4.

Tick all the English courses you have taken at ACG including the current one.

Check all

that apply.

EAP 1000

EAP 1001

EAP 1002

WP 1010 
5.

What is your level of English? *

Mark only one oval.

Basic

Intermediate

Advanced

Native-like

Native

6.

What has been your previous experience with peer review? * Mark only one oval.

\section{Never Before}

Once or Twice Before

More than Twice Before

\section{As a reviewee}

7.

As a reviewee, I found peer review helped me reduce language errors in my writing.

Mark only one oval.

Yes

No

8.

I found peer review to be as valuable as teacher review. *

Mark only one oval.

Never

Rarely

Sometimes

Most of the Time

Always 
9

I read peer feedback carefully. *

Mark only one oval.

Never

Rarely

Sometimes

Most of the Time

Always

10

As a reviewee, I revise my writing taking into account peer feedback. Mark only one oval.

Never

Rarely

Sometimes

Most of the Time

Always

11

My peer reviewers were able to identify most of the problems in my writing. ${ }^{*}$ Mark only one oval.

Never

Rarely

Sometimes

Most of the Time

Always 
12.

What aspects did peer reviewers mostly provide comments on? Click all that apply.*

Check all that apply.

grammar/syntax

vocabulary

spelling

organization

ideas

13.

As a reviewee, I found the combination of peer oral conferencing and written comments more helpful than just written comments. * Mark only one oval.

Yes

No

The same (both as helpful)

14.

Briefly explain why or why not.

15.

As a reviewee, I prefer to know the name of my peer reviewer. * Mark only one oval.

Yes

No

The same (both as helpful) 
16. As a reviewee, I found peer review to be a waste of time. * Mark only one oval.

Yes

No

The same (both as helpful)

17

Briefly explain why or why not.

\section{As a Reviewer}

18.

As a reviewer, I found the combination of peer oral conferencing and written comments more helpful than just written comments. * Mark only one oval.

\section{Yes}

No

The same (both as helpful)

19.

As a reviewer, I was more critical in giving feedback when I was doing peer review anonymously. *

Mark only one oval.

Yes

No 
20.

As a reviewer, I found peer review helped me reduce language errors in my own writing.

Mark only one oval.

\section{Yes}

No

21.

As a reviewer, I found peer review helped me improve the overall organization in my writing. *

Mark only one oval.

Yes

No

22.

As a peer reviewer, I performed peer review carefully. *

Mark only one oval.

Never

Rarely

Sometimes

Most of the Time

Always

23.

As a reviewer, I was able to identify most of the problems in the writing in my peer reviewees. *

Mark only one oval.

Never

Rarely

Sometimes

Most of the Time

Always 
24.

As a peer reviewer, I mostly provided comments on (Click all that apply). Check all that apply.

grammar/syntax

vocabulary

spelling

organization

ideas

25.

As a peer reviewer, I prefer to know the name of my peer reviewee. * Mark only one oval.

Yes

No

26.

Briefly explain why or why not.

27.

As a reviewer, I found peer review to be a waste of time. * Mark only one oval.

Yes

No

28.

Briefly explain why or why not. 


\section{Recommendation}

29

Is there anything else you would like to mention about peer review? 


\section{Appendix 2: Sample Peer Feedback Worksheet}

Extended Critical Response (Using Multiple Sources)

First Draft: Peer Review

Please evaluate your classmate's writing. This exercise is twofold: 1 . Assist your classmate in the revision process; 2 Reflect on your own writing. Thus make every effort to give constructive feedback. Refer to the prompt and articles if necessary.

Reviewer (Optional): Writer:

1. Is the introductory paragraph effective; in other words, does the writer begin with an attention getter, the name, title, publication details, and a summary of the text? Yes No If no, explain what is missing:

2. Does the writer include his/her thesis statement at the end of the introductory paragraph? Yes No

Underline the thesis statement.

3. Does the writer use effectively textual support from all the secondary sources (Tannen, Gino and WoodBrooks and Quindlen)? Yes No Which source(s) is missing?

4. Does the writer use textual evidence from the main source (Reiman) effectively? Yes No Explain your response

5. Does the writer include his/her own voice (examples, interpretations etc.)? Yes No Is it embedded coherently in the essay? Yes No If not, help the writer improve the coherence by giving an example.

6. What do you think is one of the strongest part(s) of this essay? Explain why?

7. What do you think the writer should change or add?

8. State one thing you learned from this peer review. 